\title{
Study on Lateral Vibration Offsets of freight cars Under the Condition of Shift of Center of freight Gravity on the Curve Track
}

\author{
Xue Wan \\ School of traffic and transportation \\ Beijing Jiaotong University \\ Beijing, China \\ 14125732@bjtu.edu.cn \\ Mei Han \\ School of traffic and transportation \\ Beijing Jiaotong University \\ Beijing, China \\ mhan@bjtu.edu.cn
}

\author{
Zhe Fang \\ School of traffic and transportation \\ Beijing Jiaotong University \\ Beijing, China \\ 13120834@bjtu.edu.cn \\ Nengpu Yang \\ School of traffic and transportation \\ Beijing Jiaotong University \\ Beijing, China \\ yangnengpu@163.com
}

\begin{abstract}
- the vehicle maximum lateral vibration offset is one of the premises for judging the feasibility of out-of-gauge freights transport. Dynamics simulation models of singlevehicle $\mathrm{NX}_{70 \mathrm{H}}$ flat were established by SIMPACK with American fifth track spectrum being the excitation, in order to discuss the change rules of the roll angles, the yaw angles, the lateral offsets and the maximum lateral vibration offsets when the vehicle running on Chinese I grade railway lines at the speed of $20 \sim 120 \mathrm{~km} / \mathrm{h}$ under the condition of lateral shift of center of freight gravity. Simulation results show that the running speed, the line condition and shift of center of freight gravity all have a significant impact on the roll angles and the maximum lateral vibration offset, and the yaw angles, the lateral offsets always keep the steady values, and the maximum lateral vibration offsets maximize at the end of vehicle.
\end{abstract}

Keywords-component; freight cars transportation; lateral vibration offset; SIMPACK; dynamics simulation; vehicle engineering

\section{INTRODUCTION}

The vehicle maximum lateral vibration offset is one of the premises for judging the feasibility of out-of-gauge freights transport. The vehicle lateral vibration offset was affected by many factors, and its rules for computer simulation research is very necessary for the complex accurate measurement and large requirement of manpower, I material resources [1]. Curve of track is one of the railway line three weak links, and the performance of locomotive vehicle curve has been concerned for long in the field of dynamics. In railway cargo loading, due to the limits of certain freights special shape, uneven distribution of weight and vehicle gauge and structure gauge, the projection of center of freight gravity has deviation off the vehicle central loading, which has a great impact on the lateral vibration of vehicle [2]. The maximum allowable lateral deviation of the center of freight gravity was limited
$100 \mathrm{~mm}$ in "The Rule of Railway Freights Loading and Reinforcement" [3], and it is very necessary to study the change rules of the vehicle lateral vibration by computer simulation.

Single-vehicle $\mathrm{NX}_{70 \mathrm{H}}$ flat marked loading capacity of $70 \mathrm{t}$ with $\mathrm{K} 5$ bogies was chosen as the research object to the change rules of the center of freights cars gravity in the lateral offset of $100 \mathrm{~mm}$, under the condition of the transverse vibration of offset in different line conditions.

\section{MODELING OF SINGLE-VEHICLE DYNAMICS}

\section{A. Model Explanation}

The dynamics simulation model of single-vehicle $\mathrm{NX}_{70 \mathrm{H}}$ flat consists of 20 rigid bodies: 1 car body, 1 cargo, 2 bolsters, 4 side frame, 8 axles and 4 wheel sets [4]. The rigid body degrees of freedom are shown in Table 1 (50 degrees of freedom in total)

TABLE I. DEGRES OF FREEDOM VEHICLE SySTEM

\begin{tabular}{|c|c|c|c|c|c|c|}
\hline \multirow[b]{2}{*}{$\begin{array}{c}\text { Member } \\
\text { name }\end{array}$} & \multicolumn{6}{|c|}{ Movement } \\
\hline & portrait & sway & $\begin{array}{c}\text { up and } \\
\text { down }\end{array}$ & roll & yaw & pitch \\
\hline carbody & $X_{c}$ & $Y_{c}$ & $Z_{c}$ & $\theta_{c}$ & $\beta_{c}$ & $\Phi_{c}$ \\
\hline $\begin{array}{c}\text { bolsters } \\
(\mathrm{i}=1,2)\end{array}$ & - & - & $Z_{b i}$ & - & - & $\Phi_{b i}$ \\
\hline $\begin{array}{l}\text { side frame } \\
(\mathrm{i}=1 \sim 4)\end{array}$ & $X_{t(L, R) i}$ & $Y_{t(L, R) i}$ & $Z_{t(L, R) i}$ & - & $\beta_{t(L, R) i}$ & $\Phi_{t(L, R) i}$ \\
\hline $\begin{array}{c}\text { wheel sets } \\
(\mathrm{i}=1 \sim 4)\end{array}$ & $X_{w i}$ & $Y_{w i}$ & - & $\theta_{w i}$ & $\beta_{w i}$ & $\Phi_{w i}$ \\
\hline
\end{tabular}

The model assumption were made when building the vehicle systems as follows:

(1) The entire vehicle system is symmetrical, and all components (e.g. wheel sets, side frames, bolsters) are rigid body, no elastic deformation.

(2) Without regard to the lateral wind force and the interaction of the vehicles, only consider the movements of the single-vehicle model [5]. 
Force elements are set according to the actual parameters of $\mathrm{NX}_{70 \mathrm{H}}$ flat, and nonlinear factors in the model are considered as below:

The bolster spring, damping spring, and lateral stop of the bogies are defined as force elements [6]. Vertical spring with greater stiffness is set between upper and lower center plates, upper and lower side frames, and its elastic force can be used as positive pressure in friction unit [7]. Then the friction torques of center plate, friction of side frame can be calculated. $\mathrm{NX}_{70 \mathrm{H}}$ type flat cars established in SIMPACK is shown in Fig .1.

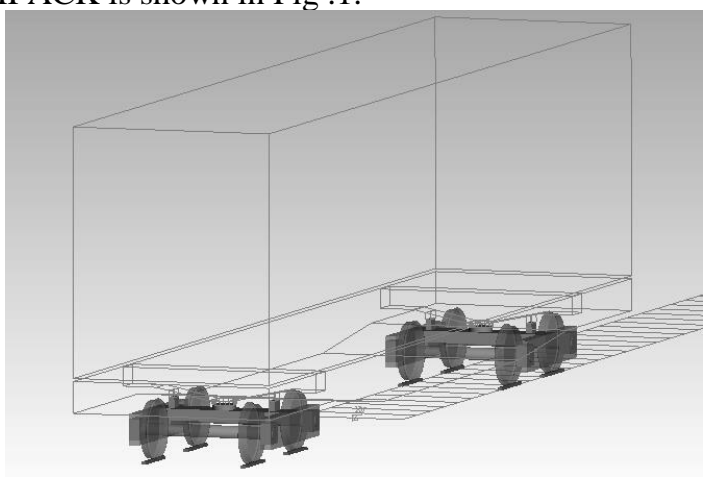

Figure 1. Diagram of Simulation of Vehicle

\section{B. Loading Scheme}

$\mathrm{NX}_{70 \mathrm{H}}$ type flat cars marked load 70t, the truck loading weight was determined as $70 t$ in the study. And the height of gravity center of the car is determined for $2400 \mathrm{~mm}$ referring to the test of Beijing Jiaotong University [9]. The lateral deviation of the center of freight gravity was determined for $100 \mathrm{~mm}$ according to "railway freight loading reinforcement rules" [3]. And in the curve, there are two kinds of cargo gravity center deviation: inside of curve track and outside of curve track, which are shown in Fig. 2 .

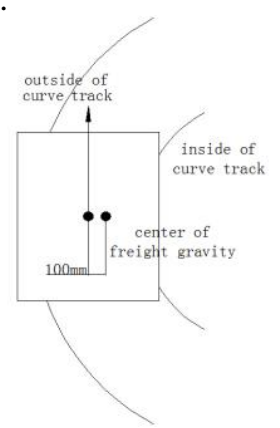

(a) Inside of Curve Track (b) Outside of Curve Track

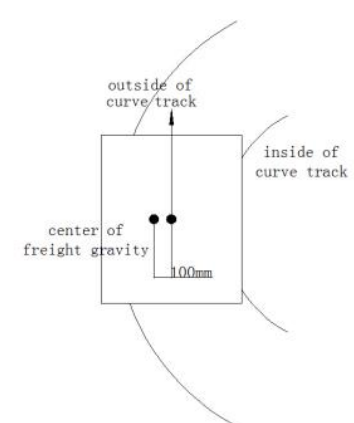

Figure 2. Two Conditions of Lateral Shift of Center of Freight Gravity

\section{Running Condition}

Referring to Line design specifications (1999) and the actual data of Jincheng line [10], radius of curve track are set as $600 \mathrm{~m}$ and $1200 \mathrm{~m}$. Considering of no complete track spectrum in our country, the AAR5 track spectrum model is choose as track irregularity of Chinese I grade railway lines and it' $s$ transformed to time-domain to fit for the simulation platform. The test scheme is shown in Table 2.
TABLE II. The Test Scheme Of Curve Track

\begin{tabular}{|c|c|c|c|}
\hline $\begin{array}{c}\text { Radius of } \\
\text { curve (m) }\end{array}$ & $\begin{array}{c}\text { Transition curve } \\
\text { length }(\mathbf{m})\end{array}$ & $\begin{array}{c}\text { Super elevation } \\
\text { of outer rail } \\
(\mathbf{m m})\end{array}$ & $\begin{array}{c}\text { Balancing } \\
\text { speed }(\mathbf{k m} / \mathbf{h})\end{array}$ \\
\hline 600 & 80 & 80 & 65.17 \\
\hline 1200 & 100 & 90 & 97.76 \\
\hline
\end{tabular}

\section{Choose of Calculation Points}

The lateral vibration offset are different with the increase of height. According to GB146.2-83(Structure Gauge for Standard Gauge Railways) Appendix A, the heights of simulation calculation points are determined: $1250 \mathrm{~mm}, 2400 \mathrm{~mm}, 3850 \mathrm{~mm}, 4300 \mathrm{~mm}, 4800 \mathrm{~mm}$, and $5300 \mathrm{~mm}[8]$.

\section{RESUltS AND ANALYSIS OF THE SIMULATION}

\section{A. The Results of the Roll Angle}

The simulation data of roll angles are shown in Fig .3. as shown in Fig .3, with the increase of the vehicle speed, when the gravity of freight is inside of the curve, the roll angle decreases, and when the gravity of freight is outside of the curve, the roll angle decreases and then increases, reaching a minimum value at less than the balancing speed. The roll angle has a big deal with super elevation and lateral deviation of the center of freight gravity. Running at a speed less than the balancing speed, the vehicle is over ultra-high state, and with the increase of the speed, the state weakens and the roll angle decreases; and running at a speed higher than the balancing speed, the vehicle is under ultra-high state, and with the increase of the speed, the state strengthens, and the roll angle increases. The gravity torque of roll will increase when the center of freight gravity has lateral deviation. When the gravity of freight is inside of the curve track, the gravity torque of vehicle rolling to the inner side of curve increase, and even the vehicle runs at a speed higher than the balancing speed, the roll angle to the inner side of the curve caused by the lateral deviation of the center of freight gravity is always bigger than that caused by the ultra-high state. So the roll angle has been decreasing. When the gravity of freight is outside of the curve, the gravity torque of vehicle rolling to the outside of curve decreases, and even the vehicle runs at a speed less than the balancing speed, the roll angle to the outside of the curve caused by the lateral deviation of the center of freight gravity is always bigger than that caused by the ultra-high state. With the increase of speed, the vehicle is under ultra-high state and begin to tilt to the outside of the curve. So the roll angle decreases and then increases. 


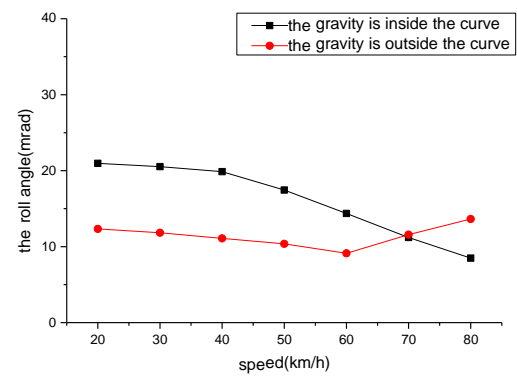

(a) $\mathrm{R} 600 \mathrm{~m}$

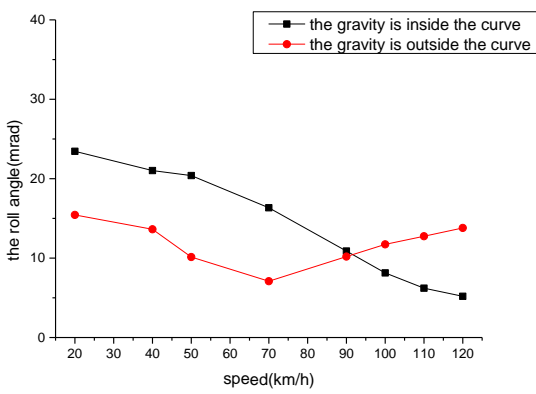

(b) R1200m

Figure 3. Simulation Results of Roll Angles

\section{B. The Results of the Yaw Angle}

The simulation data of yaw angles are shown in Fig .4. as shown in Fig .4, even the vehicle speed has increase and the center of freight gravity has lateral deviation, the yaw angle always is not large. When the freight car is running on the tangent track, the gyroscopic moments generated by center plates and the constant contact resilient side bearings suppress the motion of the yaw vibration.

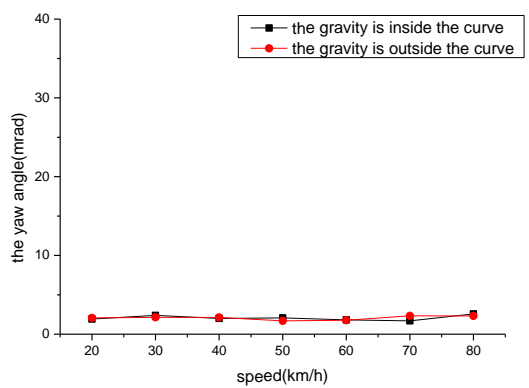

(a) R600m

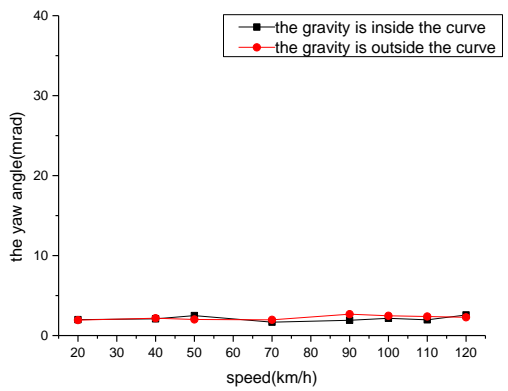

(b) R1200m

Figure 4. Simulation Results of Yaw Angles

\section{The Results of the Lateral Offset}

The simulation data of yaw angle are shown in Fig .5. As shown in Fig .5, the lateral stiffness provided by primary and secondary suspension of $\mathrm{K} 5$ bogie restrain lateral offset.

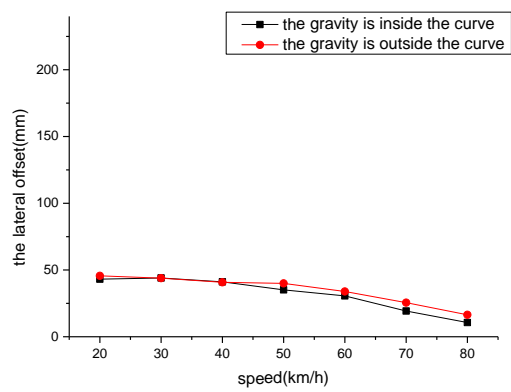

(a) $\mathrm{R} 600 \mathrm{~m}$

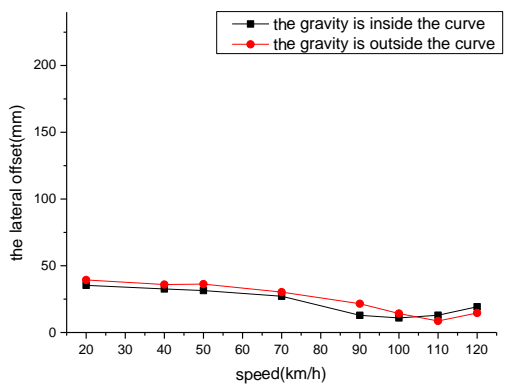

(b) R1200m

Figure 5. Simulation Results of Lateral Offset.

D. The Results of the Maximum Lateral Vibration Offset

It is found that the maximum lateral vibration offset is the result of the combined action of the roll vibration, yaw vibration and lateral vibration. The simulation data of the maximum lateral vibration offset are shown in Fig .6.

As shown in Fig .6, as for R600m curve and R1200m curve, at each speed level, the maximum lateral vibration offsets of vehicle end are larger than that of vehicle center. Cause of the center of yaw vibration locates in the central of vehicle, so the vibration offsets produced by yaw vibration is null. But little gap of them proof that the yaw vibration accounts for the little proportion of the maximum lateral vibration offset. The maximum lateral vibration offset has the similar change with the roll angle, proofing that the lateral offset generated by the roll vibration accounts for the largest proportion of the maximum lateral vibration offset. 


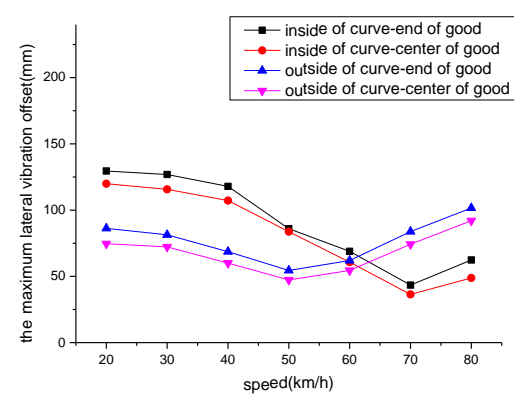

(a) R600m

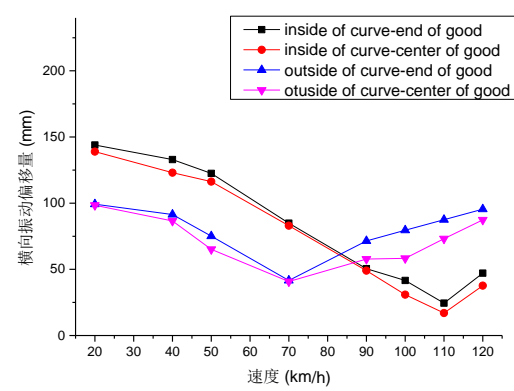

(b) R1200m

Figure 6. Simulation Results of the Maximum Lateral Vibration Offset

\section{CONCLUSION}

The results are clearly shown as below: the running speed, the line condition and shift of center of freight gravity all have a significant impact on the roll angles and the maximum lateral vibration offset.

(1) When the gravity of freight is inside of curve, the roll angle decreases, and when the gravity of freight is outside of the curve, the roll angle decreases and then increases, reaching a minimum value at less than the balancing speed.
(2) The yaw angles and the lateral offsets always keep the steady values.

(3) The maximum lateral vibration offset has the similar change with the roll angle, proofing that the lateral offset generated by the roll vibration accounts for the largest proportion of the maximum lateral vibration offset.

(4) Running at the same speed, the maximum lateral vibration offsets of vehicle end are larger than that of vehicle center. And the maximum lateral vibration offset appears at the end of vehicle.

\section{REFERENCES}

[1] Dianming Ju. "Research of out of gauge goods transportation basic theory and its application," Beijing: Beijing Jiaotong University Press, 1997.

[2] Yongzhao Peng. "Experimental research on the mechanism and Simulation of the effect of operating conditions on the safety of vehicle operation load of railway freight cars," Beijing: Beijing Jiaotong University Press, 2013

[3] The Ministry of Railway of the People's Republic of China. The Rule of Railway Goods Loading and Reinforcement, Beijing: China Railway Press, 2012.

[4] [4] Junmao Yan, Cheliang Gongcheng, Beijing: China Railway Press, 2008.

[5] Zunsong Reng, Cheliang Xitong Donglixue, Beijing: China Railway Press, 2007.

[6] Suxia Zhou, Instance Tutorial of SIMPACK, Beijing: Beijing Union Publishing Company, 2013.

[7] Chao Chen, "The Research on Lateral Stiffness of Railway Truck Bogie," Railway Transportation and Economy, vol. 4, 2010.

[8] Hao Xu, "Influence of Vehicle Conditions on the Lateral Vibration Offset of The High-Speed Train," Railway Standard Design, vol 10, 2013.

[9] Beijing Jiaotong University, China Academy of Railway Sciences: Report on Gravity Center Height on Running Safety of Loaded Double-stack Container Car, Beijing: Jiaotong University, 2007.

[10] The Ministry of Railway of the people' s Republic of China Railway Line Design Specifications (GB50090-99) .S. Beijing: China Planning 1999. 